\section{Missing pebble in the mosaic of rheumatic diseases and mental health: younger does not always mean happier}

We have read with great interest the article by Redeker $e t a l^{1}$ investigating the determinants of psychological well-being in axial spondyloarthritis $(\mathrm{SpA})$. The authors observed that among 1736 patients aged $18-79$ years, $68 \%$ of subjects displayed depressive symptoms, ranging from mild to severe according to the five-item WHO Well-Being Index. This article clearly points out the burden of depressive symptoms in patients with SpA and its correlation with disease activity, functional impairment and other parameters including younger age. The authors emphasise that a potential explanation for the negative association between depressive symptoms and age might be a better capability to cope with the disease of adult compared with young patients. This aspect prompted our reflections, as the psychological impact of rheumatic and musculoskeletal diseases (RMDs) in young people is a major unmet need.

We previously reported that over $90 \%$ of young patients with RMDs outline an impact of their condition on mental health which, based on the definition of $\mathrm{WHO},{ }^{2}$ encompasses depressive symptoms and anxiety and the fear to not be accepted as full members of the society due to the disease. ${ }^{3}$ The spectrum of psychological discomfort in young people with RMDs is also related to their career stage (eg, if looking for a job or being employed for just a few years), the kind of job qualification (eg, employment in a physically demanding job may amplify negative feelings), as well as private life matters. With regard to the latter, being in a stable relationship may help coping with the disease, but some partners, particularly in young age, may not be supportive or willing to adapt to the partner's needs.

Previous studies including adult patients revealed that a consistently lower percentage of them, only $30 \%-60 \%$, report an impact of their disease on mental health. ${ }^{45}$ These latter percentages fit with the results obtained by Redeker et al in their cohort, which includes the complete age range from 18 years to 79 years. Specific conclusions regarding the actual burden of depression for specific age groups of patients with SpA may not become apparent from the multivariable logistic model. In this regard, it is interesting to note that the study from Meesters et al ${ }^{6}$ depicts higher depression rates in patients with ankylosing spondylitis aged below 50 years. Considering this, can we be sure that the rates are not substantially different in patients below the age of 35 years, or even more so in young patients who had just made the often challenging transition from adolescence to adulthood? How impactful on mental health is being confronted with a chronic disease in early adulthood, not knowing how this may affect the own future? Another interesting point for discussion is the impact of comorbidities and disease activity on mental health. Among the wide spectrum of comorbidities in RMDs, some are closely depending on the patients' age, and data from the Consortium of Rheumatology Researchers of North America registry reveal that at least in rheumatoid arthritis, the overall prevalence of comorbidities is higher in older patients. These subjects are less likely to achieve disease remission. ${ }^{7}$ Furthermore, pain might not necessarily correlate with disease activity in SpA as in other RMDs, hence it should be considered as a separate domain that can independently affect psychological well-being. ${ }^{8-10}$ It would therefore be very interesting to see whether data gathered from Redeker $e t$ al in SpA would mirror those observed in RA, and how the prevalence of depressive symptoms, comorbidities, disease activity, pain and their interactions vary in different age ranges. This would allow understanding how the balance of powers of disease activity, comorbidities and age specifically influences depressive symptoms/ health status in patients with SpA. In conclusion, we acknowledge that the study by Redeker et al provides major insights into this field and points out the need of a prompt intervention to identify and address psychological needs of patients with SpA. However, looking at the overall mosaic of psychological well-being in $\mathrm{SpA}$, we might miss a specific pebble relating to the unique experience of young people dealing with the disease in a peculiar phase of their life. We believe that a deeper understanding of the specific burden of $\mathrm{SpA}$ and, in general terms, of RMDs on mental health in patients of different age would allow to tailor approaches to be eventually implemented in clinical practice.

Alessia Alunno, ${ }^{\circ 1}$ Paul Studenic, ${ }^{2}$ Dieter Wiek, ${ }^{3,4}$ Petra Balážová,
Daniel Aletaha
${ }^{5}$ Rheumatology Unit, Department of Medicine, University of Perugia, Perugia, Italy
${ }^{2}$ Division of Rheumatology, Department of Internal Medicine 3, Medical University
Vienna, Vienna, Austria
${ }^{3}$ EULAR PARE, Zurich, Switzerland
${ }^{4}$ Deutsche Rheuma-Liga, Bonn, Germany
${ }^{5}$ EULAR Young PARE, Zurich, Switzerland
${ }^{6}$ Slovak League Against Rheumatism, Piestany, Slovakia

Correspondence to Dr Alessia Alunno, Rheumatology Unit, Department of Medicine, University of Perugia, Perugia I-06129, Italy; alessia.alunno82@gmail.com

Handling editor Francis Berenbaum

Contributors All authors provided a substantial contribution to the article.

Funding The authors have not declared a specific grant for this research from any funding agency in the public, commercial or not-for-profit sectors.

Competing interests None declared.

Patient consent Not required.

Provenance and peer review Not commissioned; internally peer reviewed.

(c) Article author(s) (or their employer(s) unless otherwise stated in the text of the article) 2019. All rights reserved. No commercial use is permitted unless otherwise expressly granted.

\section{Check for updates}

To cite Alunno A, Studenic P, Wiek D, et al. Ann Rheum Dis 2019;78:e54.

Received 17 April 2018

Accepted 19 April 2018

Published Online First 28 April 2018

\section{Linked}

- http://dx.doi.org/10.1136/annrheumdis-2018-213620

Ann Rheum Dis 2019;78:e54. doi:10.1136/annrheumdis-2018-213611

\section{REFERENCES}

1 Redeker I, Hoffmann F, Callhoff J, et al. Determinants of psychological well-being in axial spondyloarthritis: an analysis based on linked claims and patient-reported survey data. Ann Rheum Dis 2018;77:1017-24.

2 WHO. Mental health: a state of well-being. http://www.who.int/features/factfiles/ mental_health/en/ (accessed 15 Mar 2018).

3 Alunno A, Studenic P, Nikiphorou E, et al. Person-focused care for young people with rheumatic and musculoskeletal diseases: young rheumatologists' and EULAR Young PARE perspectives. RMD Open 2017;3:e000514-6.

4 Sokolovic S, Dervisevic V, Fisekovic $S$. Mental health status can reflect disease activity in rheumatoid arthritis. Eur J Rheumato/ 2014;1:55-7.

5 Dures E, Almeida C, Caesley J, et al. Patient preferences for psychological support in inflammatory arthritis: a multicentre survey. Ann Rheum Dis 2016;75:142-7.

6 Meesters JJ, Bremander A, Bergman S, et al. The risk for depression in patients with ankylosing spondylitis: a population-based cohort study. Arthritis Res Ther 2014; 16:418. 
7 Ranganath VK, Maranian P, Elashoff DA, et al. Comorbidities are associated with poorer outcomes in community patients with rheumatoid arthritis. Rheumatology 2013;52:1809-17.

8 Studenic P, Smolen JS, Aletaha D. Near misses of ACR/EULAR criteria for remission: effects of patient global assessment in Boolean and index-based definitions. Ann Rheum Dis 2012;71:1702-5.
9 Kvrgic Z, Asiedu GB, Crowson CS, et al. "Like No One Is Listening to Me": A Qualitative Study of Patient-Provider Discordance Between Global Assessments of Disease Activity in Rheumatoid Arthritis. Arthritis Care Res 2017 (Epub ahead of Print Dec 2017).

10 Rifbjerg-Madsen S, Christensen AW, Christensen R, et al. Pain and pain mechanisms in patients with inflammatory arthritis: a Danish nationwide cross-sectional DANBIO registry survey. PLoS One 2017;12:e0180014. 